Article

\title{
Development of a Multiplex PCR Assay to Monitor Living Modified Cottons in South Korea
}

\author{
Dong Wook Kim ${ }^{+} \mathbb{D}$, Il Ryong Kim ${ }^{\dagger}$, Hye Song Lim, Wonkyun Choi and Jung Ro Lee * \\ National Institute of Ecology, 1210 Geumgang-ro, Maseo-myeon, Seocheon-gun 33657, Korea \\ * Correspondence: leejr73@nie.re.kr (J.R.L.) \\ † These authors contributed equally to this work.
}

Received: 11 June 2019; Accepted: 27 June 2019; Published: 1 July 2019

\begin{abstract}
Cotton has been cultivated worldwide and is a useful crop for humans. However, all living modified organisms (LMOs), including living modified (LM) cotton, are not cultivated in South Korea and are imported from overseas. LM cotton imports are on the rise and most of the imported cotton is used as livestock feed. In particular, it is commonly used to feed Holstein breeds that produce milk, because cotton improves the quality of milk. However, as the cotton imports increase, the possibility of unintentional outflows in the distribution process also increases. Consequently, there is an increasing concern about unintentional release of LM cotton into the natural environment. Therefore, environmental monitoring and post-management of LMOs are very important steps. Recently, a total of 30 LM crop events were approved for LM cotton import in South Korea. A single detection method has been used to monitor individual events. However, a single method of detection for collected samples requires a large number of PCRs, with obvious disadvantages. Therefore, a simultaneous detection method was developed for 8 representative events (GHB119, GHB614, MON88913, MON15985, LLCOTTON25, MON1445, 281-3006, and MON531) in an effort to monitor 26 of them and facilitate the identification of LM cotton. The results suggest that our new multiplex PCR method may be useful for monitoring and post-management of LM cotton.
\end{abstract}

Keywords: living modified organism; monitoring; multiplex PCR; feedstuffs

\section{Introduction}

Cotton, which belongs to the genus Gossypium L., in the family Malvaceae, is used worldwide for the lint on its seed coat [1]. The cotton fiber is used for manufacturing cloth and cottonseed is used for feeding ruminant animals [2,3]. Cotton is one of the major living modified (LM) crops; other LM crops include soybeans, maize, and canola [4]. The yield and cultivation area of LM crops have been increasing every year since their initial commercialization. Of the 30.1 million hectares of global cotton cultivation area, LM cotton plantations constitute 24.1 million hectares $(80 \%)$, which accounts for $13 \%$ of the total LM crop cultivation area in 2017 [4]. In 2016, India's LM cotton cultivation area was the largest in the world at 10.8 million hectares, followed by the United States at 3.7 million hectares, China at 2.78 million hectares, and Pakistan at 2.9 million hectares. In the United States and India, 93\% and $96 \%$ of the produced cotton, respectively, is LM cotton [5].

In South Korea, the cultivation of LM crops are not permitted but imports of LM crops including LM cotton are allowed for food, feed, or processing [6]. Therefore, a large amount of LM cotton is imported every year as feed for ruminant animals. In 2017, 170,000 tons of cotton was imported by South Korea and about $90 \%$ of it was LM cotton $[7,8]$. Therefore, there is an increasing concern in South Korea about unintentional release of LM cotton into the natural environment.

Seven ministries under the Korean government have individual national authority on the use of LM plants, as laid out by the "Transboundary Movement, etc., of Living Modified Organisms Act" 
(herein referred to as The Law). According to The Law, the Ministry of Environment (MOE) is in charge of affairs related to living modified organisms (LMOs) "used to reduce or remove environmental pollutants or to restore the environment," and "effects on natural ecosystems."

Since 2009, the MOE and National Institute of Ecology (NIE) have been conducting The Environmental LMO Monitoring and Post-Management Project $[9,10]$. In the project, the natural environmental leakage of LM crops such as cotton, maize, soy bean, and canola was monitored and the risk assessment and management of released LMOs was performed [11-13]. A specific LMO detection method is crucial to determine whether the samples collected in this project contain LMOs [14,15].

Recently, a total of 30 LM cotton events including single and stack LMOs were approved in South Korea. A previous study reported LM cotton multiplex detection methods for six events [13]. As approval and unintentional release of LM cotton events have been increasing every year, we needed to develop a new method which can detect almost approved LM cotton events. In this study, we developed a multiplex PCR method to detect eight single LM cotton events to make up for 26 approved LM cotton events. Additionally, we applied our new detection method to suspect LM samples collected during the monitoring project and found that it was more cost-effective and time-saving than conventional methods of analyzing LM samples.

\section{Materials and Methods}

\subsection{Environmental Monitoring Methods and Plant Materials}

In 2017, the distribution of LM cotton within a $100 \mathrm{~m}$ radius of 847 sites was monitored. If samples of cotton in the field were found, the coordinates using global positioning system (GPS), survey sheets, and field photos, were recorded to note down the characteristics of the investigation sites. Some leaves of the obtained samples were taken with sterilized scissors, placed in a zipper bag, and stored at $4{ }^{\circ} \mathrm{C}$ after labeling with the sample number.

Certified reference materials (CRM) of LM cotton were used in the experiments, including GHB119 and 281-3006 from the Institute for Reference Materials and Measurements (IRMM); and GHB614, MON88913, MON15985, LLCOTTON25, MON1445, and MON531 from the American Oil Chemists' Society (AOCS). Suspected monitoring samples were collected through the environmental monitoring of LMOs carried out by the NIE in 2017.

\subsection{Immunochemical Strip Kit Test}

The immunochemical strip kit test is widely used as an analytical method for the detection of expressed proteins in LM cotton. The test was immediately conducted using collected samples in the monitoring sites according to the manufacturer's protocol of the lateral flow QuickComb Kit (Envirologix, USA). The cotton leaf was ground using a pestle in a $1.5 \mathrm{~mL}$ tube and $0.7 \mathrm{~mL}$ of buffer solution was added to the it. Subsequently, four kinds of strip kits that can detect event specific proteins (2 M EPSPS, CP4 EPSPS, CRY2A/CRY1A, and PAT/BAR) were placed in the tube and allowed to react for 5-10 min. If the sample was negative (non-LMO), the strip kit only showed one line: A control band. Whereas, if the sample was positive (LMO), containing a specific target protein, two or more lines of test bands appeared on the strip kit.

\subsection{DNA Extraction and Polymerase Chain Reaction for Multiplex Analysis}

The genomic DNA from the CRM and samples collected from the monitoring project were extracted using the Exgene plant SV mini kit (GeneAll, Korea). The DNA concentration and purity for each sample was determined using the NanoDrop 2000 spectrophotometer (Thermo Fishier Scientific, USA).

Each event specific primer pair was designed using genetic information and sequence data that was obtained from the Joint Research Centre-European Commission (JRC-EC) and International Service for the Acquisition of Agri-biotech Applications (ISAAA) [16,17]. The acyl carrier protein 1 (ACP1) 
region was used for specific endogenous genes of cotton [18]. The primer set for each event for the multiplex-PCR was designed using event specific regions.

Polymerase chain reaction (PCR) was performed using 2xEF-Taq PCR pre-mix (Solgent, Korea) containing $50 \mathrm{ng}$ of template DNA and 50-70 ng of each primer. Multiplex PCR conditions included one cycle for $30 \mathrm{~s}$ at $94^{\circ} \mathrm{C}$ (denaturation); $30 \mathrm{~s}$ at $65^{\circ} \mathrm{C}$, while reducing the temperature by $0.7^{\circ} \mathrm{C}$ per cycle (annealing); and $1 \mathrm{~min}$ at $72{ }^{\circ} \mathrm{C}$ (extension); followed by 23 cycles for $30 \mathrm{~s}$ at $94{ }^{\circ} \mathrm{C}, 30 \mathrm{~s}$ at $56^{\circ} \mathrm{C}$, and $1 \mathrm{~min}$ at $72{ }^{\circ} \mathrm{C}$ [19]. The genomic DNA was amplified using the ProFlex PCR System (Applied Biosystems, USA). Amplified products were separated by electrophoresis on a $2.0 \%$ agarose gel and the gel images were visualized and analyzed using the ChemiDoc XRS+ Imaging System (Bio-Rad, USA).

\section{Results and Discussion}

\subsection{LMO Monitoring in the Natural Environment for Cotton}

In 2017, a review of LMO environmental monitoring involving LM cotton in 6 provinces, including Gyeonggi-do, Gyeongsang-do, Chungcheong-do, Jeolla-do, Gangwon-do, and Jeju-do, was carried out. As the Korean government manages all LMO information such as import ports, roadsides, stockbreeding farmhouses, and feed factories, the MOE and NIE monitored 847 natural environmental sites nearby those places to reduce or remove potential risk from LMO release. A total of 138 suspected samples of released LM cotton in 58 sites were collected through direct observation and 9 sites were selected for this study (Figure 1A,B). It is possible that LM cotton feed was dropped during transport from ports of import to feed mill or stalls, and some LM crops have been found. Collected samples were analyzed through the following procedures: Strip kit test, PCR, and nucleotide sequencing. To ascertain whether the suspected LM samples contained newly expressed proteins such as 2M EPSPS, CP4 EPSPS, CRY2A, CRY1A, and PAT/BAR, four strip kit tests were conducted. Each strip kit has a control band and positive band; the positive band determines LM crops from suspected samples (Figure 1C). As a result of strip kit test, LM cotton was found in the six sites, d, e, f, g, h, and i (Figure 1C).

\subsection{The Necessity of Multiplex PCR}

The strip kit test can detect newly expressed proteins but cannot detect specific event names of LM samples. In order to determine the correct event names of LMOs from the collected samples, the NIE has annually developed a single detection method for the approved LM crops. In 2017, a single detection method was developed for a total of eight cotton events. However, a single detection method for collected samples requires a large number of PCR reactions, with obvious disadvantages, such as requiring a long time and the high cost. Therefore, development of simultaneous detection methods was necessary for 8 representative LM events to save workforce and cost per sample. Although a total of 1104 PCR reactions using a single PCR method are required to analyze 138 suspected samples, only 138 PCR reactions using our new multiplex PCR method are enough to investigate them. 


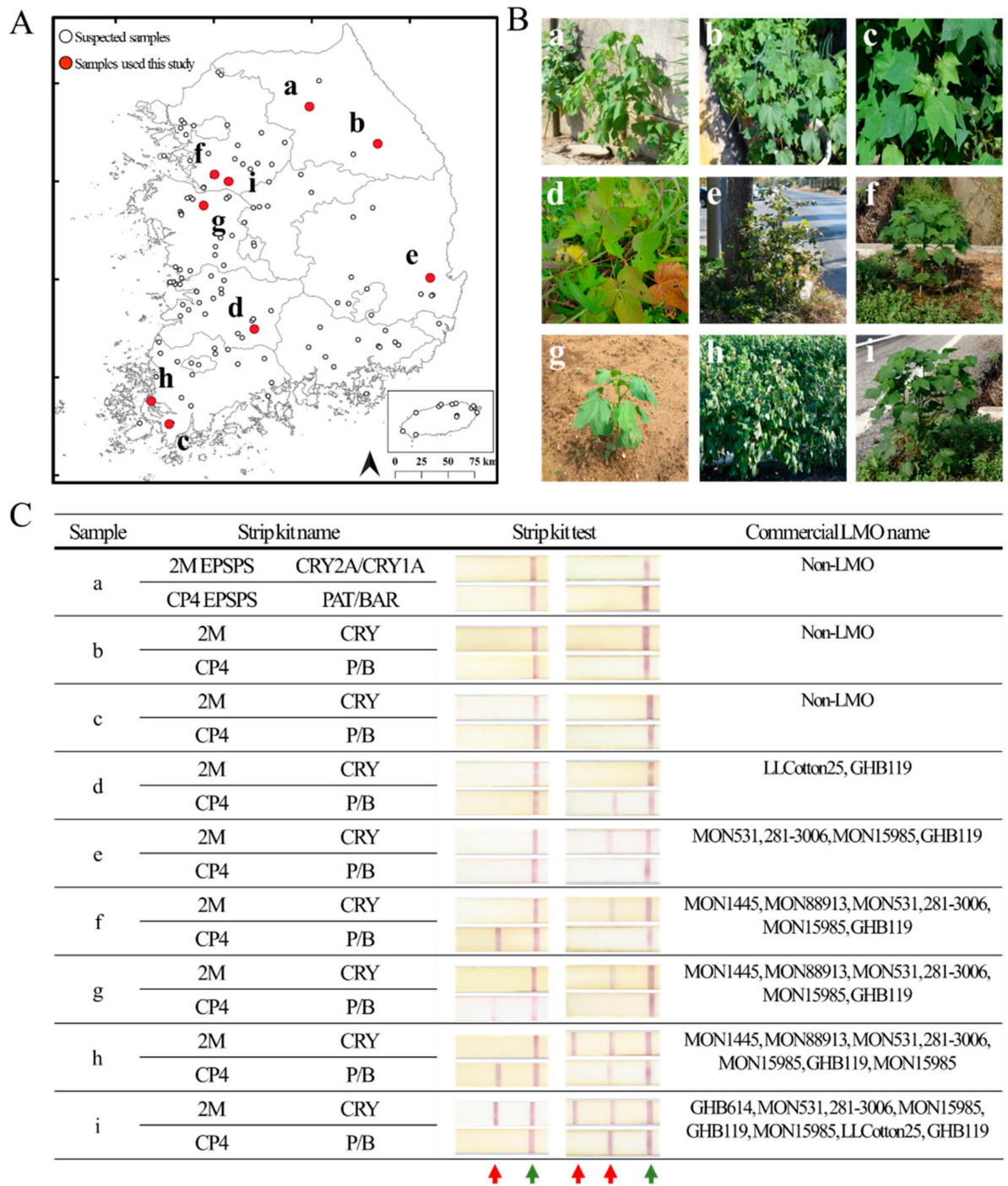

Figure 1. Result of living modified organism (LMO) environmental monitoring of cotton and strip kit test in 2017. (A) Location of suspected samples of living modified (LM) cotton in environmental monitoring (white spot; suspected samples, red spot; samples used this study). (B) Field photo of suspected LM cotton used in this study in nine sites. (C) Result of strip kit tests (2 M: 2 M EPSPS; CRY: CRY2A/CRY1A; CP4: CP4 EPSPS; P/B: PAT/BAR) and putative event (red arrows: Positive band of strip kit; green arrows: Control band of strip kit).

\subsection{Design of Event-Specific Primer Pair for Multiplex PCR}

To develop the multiplex PCR method, various sizes of primer pairs for each event were designed. Various primer pairs were tested to confirm the efficiency and accuracy of PCR. Eight primer pairs were selected in the range of 119-629 bp. Each PCR product was separated by a distance of more than $50 \mathrm{bp}$ to be visible on the agarose gel (Table 1). Each primer was designed with the cotton genome of the flanked region and the inserted DNA cassette (Figure 2). 
Table 1. New oligonucleotide primers used to detect eight LM cotton events.

\begin{tabular}{|c|c|c|c|}
\hline Event & Primer Name & Sequence $\left(5^{\prime}-3^{\prime}\right)$ & Product Size (bp) \\
\hline \multirow{2}{*}{ GHB614 } & GHB614-F & CAAATACACTTGGAACGACTTCGT & \multirow[b]{2}{*}{119} \\
\hline & GHB614-R & GCAGGCATGCAAGCTTTTAAA & \\
\hline \multirow{2}{*}{ MON88913 } & MON88913-F & CAAATTACCCATTAAGTAGCCAAATTAC & \multirow{2}{*}{164} \\
\hline & MON88913-R164 & CGAGCAGGACCTGCAGAAGCTTGA & \\
\hline \multirow{2}{*}{ MON15985 } & MON15985-F & GTTACTAGATCGGGGATATCC & \multirow[b]{2}{*}{214} \\
\hline & MON15985-R214 & GCCGTCAGGAAAACGTTCGTGACA & \\
\hline \multirow{2}{*}{ LLCOTTON25 } & LOCOTTON25-F276 & CATCATCCGTTTCTTGGACCAC & \multirow{2}{*}{276} \\
\hline & LOCOTTON25-R276 & GCCGCCTTTGTACAACCCCAGTCAT & \\
\hline \multirow{2}{*}{ MON1445 } & MON1445-2-F & GGAGTAAGACGATTCAGATCAAACAC & \multirow{2}{*}{389} \\
\hline & MON1445-2-R389 & CGTGGCCTTCTATGACCGAAGTT & \\
\hline \multirow{2}{*}{ GHB119 } & GHB119-F & CCAGTACTAAAATCCAGATCATGCA & \multirow[b]{2}{*}{450} \\
\hline & GHB119-450R & CATTAATCACACTAAAACTCGAATAAT & \\
\hline \multirow{2}{*}{ 281-3006 } & 281-3006-F & CTCATTGCTGATCCATGTAGATTTC & \multirow{2}{*}{518} \\
\hline & 281-3006-R518 & CGTTGCTCATATCCCAGGAGCTTT & \\
\hline \multirow[b]{2}{*}{ MON531 } & MON531-F270 & GGTACGGATGAGTAGGCCTACTCTT & \multirow[b]{2}{*}{629} \\
\hline & MON531-R629 & GTAGCCTCTACCTGGACAGACTCTAACC & \\
\hline $\mathrm{ACP} 1$ & ACP1-F & ATTGTGATGGGACTTGAGGAAGA & \multirow[b]{2}{*}{76} \\
\hline (Cotton endogenous) & ACP2-R & CTTGAACAGTTGTGATGGATTGTG & \\
\hline
\end{tabular}

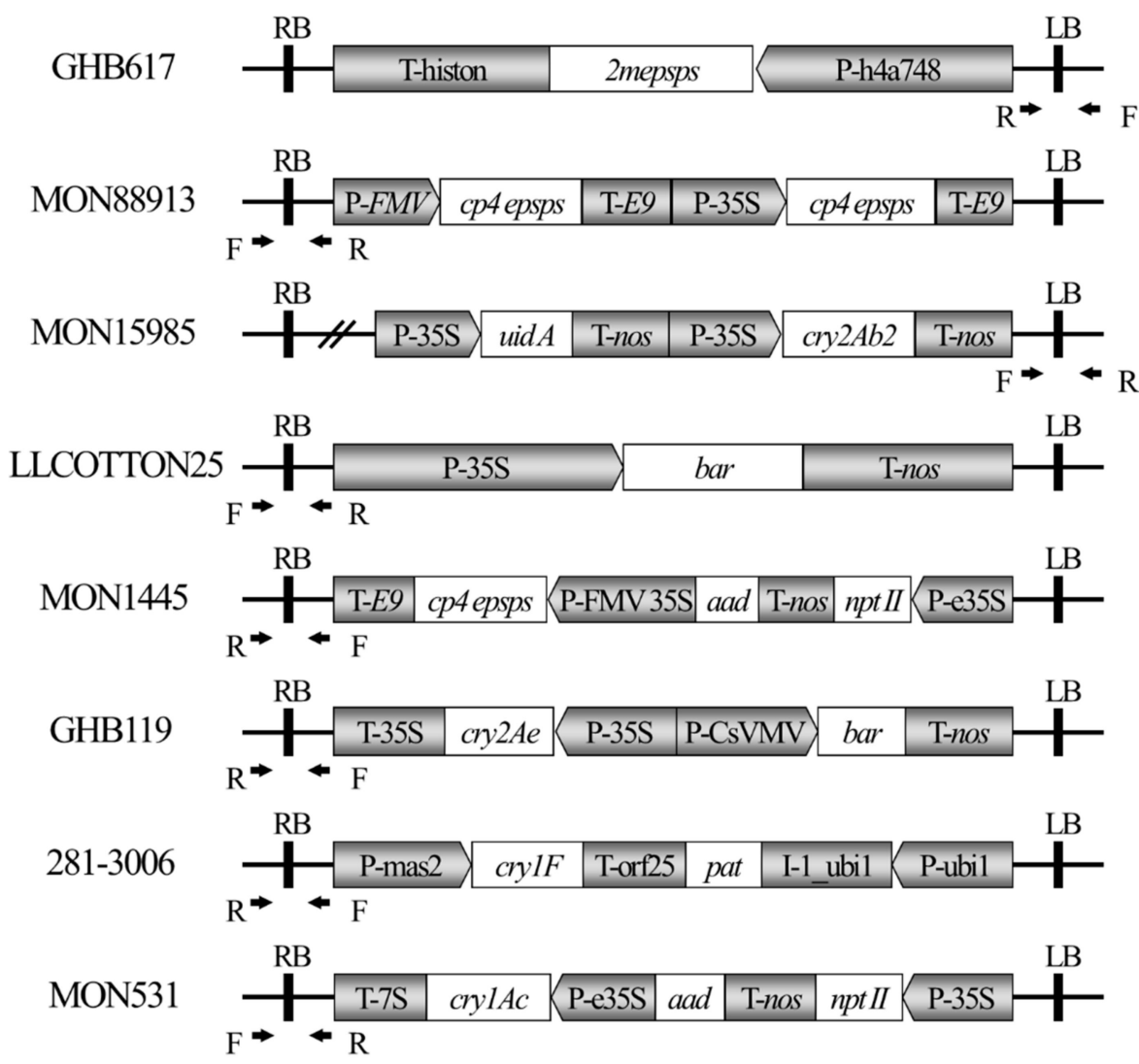

Figure 2. Schematic representations of the PCR primer positions for multiplex PCR of eight LM cotton events. Sites and direction of primers are indicated by black arrows. All primer pairs were designed with the DNA flanking region of the cotton genome and inserted DNA cassette. (LB: Left border; RB: Right border; F: Forward primer; R: Reverse primer; gray pentagon: Promoter; white square: Encoding gene; gray square: $3^{\prime}$ terminator).

\subsection{Detection of Single Event Using 8 Primer Pair Sets}

To confirm the specificity of eight primer pairs first, PCR analysis using one event genomic DNA was performed. Genomic DNA of CRMs (eight events and one non-LM) were used. As a result, the mixture of eight primer pairs showed a high level of event specificity as indicated by only a single 
band for each separate event (Figure 3). All the bands of PCR products showed the expected size for each of the eight candidate events. Those results indicated that the 8 newly designed primer pairs were not amplified to a non-specific site, but only to a desired position.

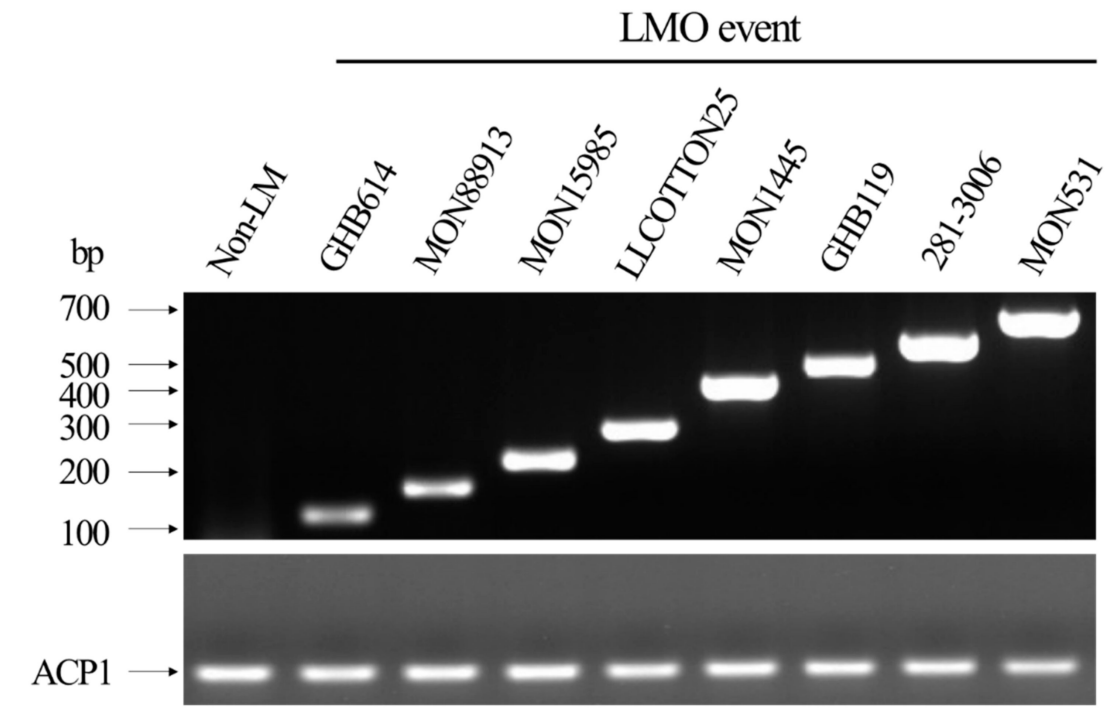

Figure 3. Gel loading analysis of PCR products of eight LM events. PCR products of Non-LM, GHB119, MON88913m MON15985, LLCOTTON25, MON1445, GHB119, 281-3006, and MON531 were electrophoresed on a 2.5\% agarose gel (Lane M: 100 bp DNA Ladder; Lane 1: Non-LM; Lane 2-9: New primers).

\subsection{Establishing the Optimal Conditions for Multiplex PCR}

Although the detection of only one event using an eight-primer mixture was confirmed by PCR analysis, most LM products were imported with stacked genes or traits that contained more than one gene. To detect multiple genes in one event at once, multiplex PCR analysis with varying conditions such as primer concentration and PCR conditions (extension time, primer melting temperature, annealing temperature, etc.) was performed. Consequentially, the primer concentration and PCR conditions played an important role. It was difficult to determine the appropriate concentration of GHB119 and GHB614 primers. Typically, the final concentration of each primer was $\sim 0.05-1 \mu \mathrm{M}$ in the PCR reaction mixture. Several tests showed that the reaction concentrations of six primer combination sets were 0.08 $\mu \mathrm{M}, 0.74 \mu \mathrm{M}$ for GHB119, and $0.41 \mu \mathrm{M}$ for GHB614, yielding eight consecutive multiplexes in a single PCR reaction (Figure 4A). The touchdown PCR method was adopted to increase the specificity of PCR amplification (Figure 4B).

\subsection{Application of the Developed Multiplex PCR Method}

A novel multiplex PCR method for $8 \mathrm{LM}$ cottons was developed and applied to nine samples from LMO monitoring in 2017. As a result, areas $\mathrm{a}, \mathrm{b}$, and c were identified as non-LM cotton. Areas d, e, $\mathrm{f}$, $\mathrm{g}$, $\mathrm{h}$, and i represented LM cotton. The sample from area $\mathrm{d}$ was identified as LLCOTTON25; area e was identified as MON531; area $\mathrm{f}$ was identified as 281-3006 $\times$ MON88913; area g identified as MON531 $\times$ MON1445; area h was identified as MON88913 $\times$ MON15985 $\times$ MON531; and area i was identified as MON15985 $\times$ MON531 $\times$ LLCOTTON25 $\times$ GHB614 (Figure 5A). Nucleotide sequencing analysis of PCR products was conducted, and all results confirmed that the target sites were amplified correctly (Figure 5B). If MON15985 and MON531 were detected at the same time, they were considered to be MON15985, because MON15985 was produced by introducing the new cassette into the MON531 [20]. The areas where LM cottons were located will be monitored further in the following years to record the rediscovery of LM cotton. Currently, there is comprehensive monitoring of LMO in South Korea, and multiplex PCR could be used for efficient utilization of the limited budget and workforce. 
A

\begin{tabular}{|c|c|c|c|c|c|c|c|c|}
\hline bp & 1 & 2 & 3 & 4 & 5 & 6 & 7 & 8 \\
\hline $700 \longrightarrow$ & & $\longrightarrow$ & $\square$ & 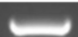 & 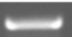 & 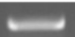 & $\square$ & 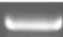 \\
\hline $500 \longrightarrow$ & & & 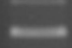 & $=$ & $E$ & $=$ & $=$ & $E$ \\
\hline 300 & & 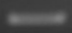 & $=$ & $\longrightarrow$ & 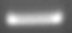 & 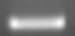 & 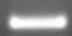 & 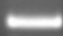 \\
\hline $200 \longrightarrow$ & & & 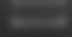 & $=$ & & & $=$ & $=$ \\
\hline 100 & & & & & & & & \\
\hline $\begin{array}{c}\text { gDNAMIX } \\
(50 \mathrm{ng} / \mu \mathrm{L})\end{array}$ & $2(\mu \mathrm{L})$ & 2 & 2 & 2 & 2 & 3 & 2 & 3 \\
\hline $\begin{array}{c}8 \text { primerset MIX } \\
(10 \mathrm{ng} / \mu \mathrm{L})\end{array}$ & 1 & 2 & 4 & 6 & 4 & 4 & 5 & 5 \\
\hline $\begin{array}{l}+\mathrm{GHB} 119 \\
(10 \mathrm{ng} / \mathrm{LL})\end{array}$ & - & - & - & - & 1 & 2 & 1 & 2 \\
\hline $\begin{array}{r}+\mathrm{GHB} 614 \\
(10 \mathrm{ng} / \mu \mathrm{L})\end{array}$ & $\begin{array}{ll}- & -1 \\
-1\end{array}$ & - & - & - & 0.5 & 1 & 0.5 & 1 \\
\hline
\end{tabular}

B

\begin{tabular}{|c|c|c|c|c|c|c|c|c|}
\hline Step 1 & \multicolumn{3}{|c|}{ Step 2} & \multicolumn{3}{|c|}{ Step 3} & \multicolumn{2}{|c|}{ Step 4} \\
\hline $94^{\circ} \mathrm{C}$ & $94^{\circ} \mathrm{C}$ & \multirow{2}{*}{$\begin{array}{c}65 \sim 56^{\circ} \mathrm{C} \\
\left(-0.7^{\circ} \mathrm{C} / \text { cycle }\right)\end{array}$} & \multirow{2}{*}{$72^{\circ} \mathrm{C}$} & $94^{\circ} \mathrm{C}$ & & & $70^{\circ} \mathrm{C}$ & \\
\hline \multirow[t]{2}{*}{$3 \mathrm{~min}$} & \multirow[t]{2}{*}{$30 \mathrm{sec}$} & & & $30 \mathrm{sec}$ & & 20 & $\frac{12 \mathrm{C}}{10 \mathrm{~min}}$ & \\
\hline & & $30 \mathrm{sec}$ & & & $30 \mathrm{sec}$ & & & $4^{\circ} \mathrm{O}$ \\
\hline 1 cycle & & 13 cycle & & & 25 cycle & & & $\infty$ \\
\hline
\end{tabular}

Figure 4. Multiplex PCR experiments were performed under various conditions. (A) Electrophoresis gel image using multiplex eight primer PCR method on LM cotton with varying conditions, including concentration of genomic DNA and eight primer sets. (B) Schematic diagram of the optimal multiplex PCR conditions.

A

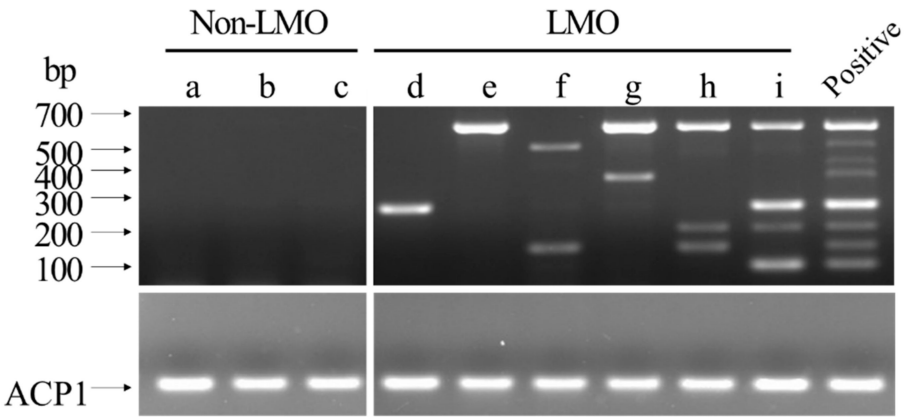

$\mathrm{B}$

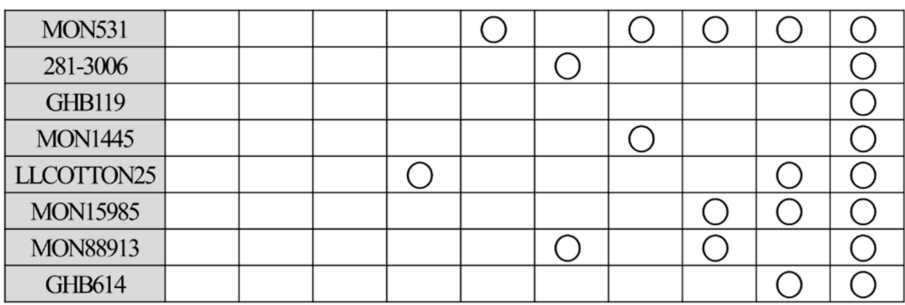

Figure 5. Application of the multiplex PCR method for the collected, candidate LM cotton samples by LMO monitoring. (A) Analysis of multiplex PCR. (B) Determination of events confirmed by nucleotide sequencing analysis. The circles indicate detected events (area a: Non-LMO; area b: Non-LMO; area c: Non-LMO; area d: LLCOTTON25; area e: MON531; area f: 281-3006 × MON88913; area g: MON531 $\times$ MON1445; area h: MON88913 × MON15985; area i: MON15985 × MON531 $\times$ LLCOTTON25 $\times$ GHB614; line p: Eight cotton events). If MON15985 and MON531 were detected at the same time, they were considered MON15985. 


\section{Conclusions}

LM Cotton is widely used worldwide for feed and as cloth. In South Korea, the use of cotton is dependent on imported LM cotton. An increase of the unintentional release of LM cotton into the natural environment owing to increasing LM cotton imports has been occurring. The NIE has been developing a method more effective than conventional PCR for LMO detection, to save costs and time. In this study, we developed a novel multiplex PCR method for eight LM cotton events and applied this method to nine samples obtained from natural environmental monitoring. The result of its application showed that the separation of LMO/non-LMO and specific LM cotton events was successful. This multiplex method for analysis of suspect LM samples has the advantages of higher accuracy, convenience of comparing results, and reducing the number of analyses compared to conventional PCR. Hence, this method would be useful as a powerful tool for environmental monitoring and post-management of LMO in many countries as well as South Korea.

Author Contributions: D.W.K., I.R.K., H.S.L., and J.R.L.; Methodology, D.W.K., I.R.K., and W.C.; Validation, D.W.K., I.R.K., H.S.L., and J.R.L.; Formal analysis, I.R.K., H.S.L., and J.R.L.; Investigation, D.W.K., I.R.K., H.S.L., and W.C.; Resources, D.W.K., I.R.K., and J.R.L.; Data curation, D.W.K., I.R.K., and J.R.L.; Writing-original draft preparation, D.W.K., I.R.K., and J.R.L.; Writing—review and editing, D.W.K., I.R.K., and J.R.L.; Visualization, J.R.L.; supervision, D.W.K., and J.R.L.; Project administration, J.R.L.; Funding acquisition.

Funding: This research was supported by a grant from the National Institute of Ecology (NIE), funded by the Ministry of Environment (MOE) of the Republic of Korea (NIE-A-2019-06 and NIE-A-2019-07).

Conflicts of Interest: The authors declare no conflict of interest.

\section{References}

1. Small, R.L.; Wendel, J.F. Phylogeny, duplication, and intraspecific variation of $A d h$ sequences in new world diploid cottons (Gossypium L., Malvaceae). Mol. Phylogenet. Evol. 2000, 16, 73-84. [CrossRef] [PubMed]

2. Osti, N.P.; Pandey, S.B. Use of whole cotton seed and cotton seed meal as a protein source in the diet of ruminant animals: Prevailing situation and opportunity. In Proceedings of the 6th National Workshop on Livestock and Fisheries Research 2006, Kathmandu, Nepal, 1-2 July 2004; pp. 111-119.

3. Arieli, A. Whole cottonseed in dairy cattle feeding: A review. Anim. Feed Sci. Technol. 1998, 72, 97-110. [CrossRef]

4. ISAAA. Global status of commercialized biotech/GM crops: 2017. ISAAA Brief. 2017, 53, 102-103.

5. SAAA. Global status of commercialized biotech/GM crops: 2016. ISAAA Brief. 2016, 52, 91.

6. Arujanan, M.; Teng, P.S.P. Legal, Regulatory and Labelling Status of Biotech Crops. In Advances in Botanical Research, 1st ed.; Kuntz, M., Ed.; Academic Press: London, UK, 2018; Volume 86, pp. 46-88.

7. FAOSTAT. Available online: http://www.fao.org/home/en (accessed on 20 August 2018).

8. KBCH. Available online: https://www.biosafety.or.kr/sub/info.do? $\mathrm{m}=030202 \& \mathrm{~s}=\mathrm{kbch}$ (accessed on 7 June 2019).

9. Shin, S.Y.; Moon, J.C.; Choi, W.; Kim, I.R.; Jo, B.-H.; Lee, J.R. Detection and environmental unintentional release monitoring of living modified maize (Zea mays L.) in Gyeonggi-do of South Korea in 2014. J. Plant Biotechnol. 2018, 45, 77-82. [CrossRef]

10. Lee, J.R.; Kim, D.W.; Kim, I.R.; Choi, W.; Park, J.H.; Jung, Y.J.; Seol, M.-A.; Eum, S.-J.; Lim, H.S.; Hwang, J.E. Study on Environmental Monitoring and Post-Management of LMO; National Institute of Ecology: Seocheon-gun, Korea, 2017; pp. 3-6.

11. Shin, S.Y.; Lim, H.-S.; Seol, M.-A.; Jung, Y.J.; Kim, I.R.; Song, H.R.; Lee, J.R.; Choi, W. Four multiplex PCR Sets of 11 LM Maize for LMO environmental monitoring in Korea. J. Plant Biotechnol. 2016, 43, 473-478. [CrossRef]

12. Choi, W.; Seol, M.-A.; Jo, B.-H.; Kim, I.R.; Lee, J.R. Development and application of a novel multiplex PCR method for four living modified soybeans. Appl. Biol. Chem. 2018, 61, 635-641. [CrossRef]

13. Jo, B.-H.; Seol, M.-A.; Shin, S.Y.; Kim, I.R.; Choi, W.; Eum, S.-J.; Song, H.-R.; Lee, J.R. Multiplex PCR method for environmental monitoring of approved LM cotton events in Korea. J. Plant Biotechnol. 2016, 43, 91-98. [CrossRef] 
14. Bektaş, A. A Multiplex, Fluorescent, and Isothermal Method for Detecting Genetically Modified Maize. Food Anal. Methods 2018, 11, 686-692. [CrossRef]

15. Kamle, S.; Ali, S. Genetically modified crops: Detection strategies and biosafety issues. Gene 2013, 522, 123-132. [CrossRef]

16. Joint Research Centre. Available online: http://gmo-crl.jrc.ec.europa.eu/gmomethods (accessed on 11 June 2019).

17. ISAAA. Available online: http://www.isaaa.org/gmapprovaldatabase/default.asp (accessed on 11 June 2019).

18. Mazzara, M.; Cordeil, S.; van den Eede, G. Event-specific method for the quantification of cotton event MON 88913 using real-time PCR; Publications Office of the European Union: Luxembourg, 2009; pp. 4-10. ISBN 978-92-79-14980-1.

19. Vos, P.; Hogers, R.; Bleeker, M.; Reijans, M.; Lee, T.v.d.; Hornes, M.; Friters, A.; Pot, J.; Paleman, J.; Kuiper, M. AFLP: A new technique for DNA fingerprinting. Nucleic Acids Res. 1995, 23, 4407-4414. [CrossRef] [PubMed]

20. Pidugu, V.K.; Pothula, R.K.S.; Narra, D.; Srivatsava, V. Development of a multiplex Polymerase Chain Reaction method for specific detection of Genetically Modified Cotton Events MON 531 and MON 15985. Int. J. Sci. Basic Appl. Res. 2012, 1, 45-52.

(C) 2019 by the authors. Licensee MDPI, Basel, Switzerland. This article is an open access article distributed under the terms and conditions of the Creative Commons Attribution (CC BY) license (http://creativecommons.org/licenses/by/4.0/). 